REGULAR ARTICLE

\title{
ECONOMETRICS OF ENVIRONMENTAL VALUATION: THE BAYESIAN INFERENCES ON WILLINGNESS TO PAY ESTIMATIONS
}

\author{
Inibehe George UKPONG
}

Address:

Department of Agricultural Economics \& Extension, Federal Polytechnic, Ekowe, Bayelsa State, Nigeria Email address: inibeheukpong@gmail.com.

\begin{abstract}
This study applied the Bayesian approach to estimate people's willingness to pay (WTP) for mitigation of environmental hazards in oil producing areas in Nigeria. The Bayesian approach enabled estimation of the mixed logit model employing the normal and log-normal distributions of WTP parameters. The model estimate indicating a negative WTP values for the status quo (STAQUO) attribute suggests that people in oil producing areas in Nigeria do not like the current welfare situation and environmental condition which are characterised by environmental problems, affecting adequate use of resources and ecosystem services. The results also show a comparatively higher WTP for food safety (FOODSAF), poverty rate (POVERTY) and unemployment rate (UNEMP) respectively, suggesting people's desire for mitigation of undesirable livelihood (welfare) impacts of resource exploitation. On the other hand, the results also indicate posi tive WTP coefficients for land and water pollution from oil spills (SPILL), gas flaring (GFLARE) and land occupied by oil and gas pipelines (LOCC), suggesting that majority of the people are in support of mitigation strategies or policy change that would ensure significant reduction in environmental pollution, gas flaring, and land-take by oil and gas companies. Oil and gas companies are encouraged to ensure mitigation of environmental and livelihood impacts of the crude oil and gas extraction, including reduction in gas flaring, based on environmental laws and global best drilling practices. The study further recommends application of the willingness to pay approach as an important strategy for assessing the values of environmental resources and the impact of resource use.
\end{abstract}

Keywords: Environmental valuation, Bayesian approach, willingness-to-pay, choice experiment, Nigeria JEL: Q1, Q4, Q5

\section{INTRODUCTION}

Environmental valuation enhances efficient use of resources. Environmental resources can be valued based on people's preferences as may be revealed by individual choices. The choices may be based on the market value (market price), or the utility (stated preference) which an individual derive from the use or mere existence of the resource. The revealed preference techniques to environmental resource valuation considers the demand for environmental resources or its value by examining the value of the related goods in the private market. In other words, it considers the value of a particular resource with reference to the prevailing market value of related goods or services. Moreover, apart from using direct market values where these are provided to estimate the value of a particular resource, the revealed preference method also uses other known methods such as the hedonic price method and the travel cost methods (Garrod \& Willis, 2001; van Berkel \& Verburg, 2014). The hedonic price method considers the value of a given resource as may be decomposed into the value of its individual characteristics and has been widely used in estimating the value of a house, recreational centre or a resource where surrounding characteristics are also valued to make up the whole value of the resource. The travel cost method is a demand estimating technique, where the value of a given resource is estimated based on the value of transport expenses incurred by the consumers to visit the site of the resources (Loomis \& McTernan, 2014; Fuleky et al., 2014). The revealed preference method of measurement also considers valuation methods based on surrogate market scenarios. It is, however, an indirect approach which assesses the market value of a particular environmental resource as well as, change in environment quality (Zeneli, 2014).

On the other hand, the expressed preference or stated preference method of environmental valuation considers the estimation of an individual value of an environmental resource or willingness to pay for a particular resource or its change. It is also market-based but depends on hypothetical or constructed market scenarios (Akujuru \& Ruddock, 2014). The technique enhances derivation of the demand curve without recourse to complementary or substitute resource (Garrod \& Willis, 2001). The stated preference method captures the utility gained upon the use or existence of a given environmental resource, hence, people are often asked to value a given resource based on the utility they claim upon it. In other words, while the revealed preference technique relies on actual, observedmarket information revealed indirectly by purchases of market goods and services related to the environmental resource, the stated preference technique captures directly the value of a resource through market simulation such 
that individuals are allowed to state their willingness to pay or accept for the resource or changes in its quality (Nijkamp, 2008). The stated preference techniques include the conjoint analysis (CA), contingent valuation (CV) and choice experiment (CE) techniques (Bachmann \& van der Kamp, 2014).

The conjoint analysis (CA) is a choice based experiment designed to collect data consistent with the random utility theory. It enables individuals to score a set of alternatives with each having random varied attributes (Hainmueller et al., 2014). It also enables the prediction of choices made by a group of individuals and measures people's preferences and trade-off decisions (Acosta $\boldsymbol{e t}$ al., 2014). The CA is a useful technique in marketing research and provides the convenience of assessing price sensitivity to price differences, and ease in assessing the competitive effect on choice, and the use of the estimated model to predict real market place choices (Rao, 2014).

The Contingent valuation (CV) methods have been widely used in valuing non-market environmental resources with specific applications in environmental accounting and the benefit-cost analysis (Piriyapada, \& Wang, 2014; Jang, et al., 2014), and changes from the status quo are often tested for acceptance using consumer (people) willingness to pay and WTA (Lienhoop \& MacMillan, 2007). Apart from its application in determining people's willingness to pay, the CV has been useful in evaluating people's willingness to accept (WTA) compensation for specific environmental resources or changes in the status of the resource (Zhen et al., 2014; Amigues, et. al., 2002). Contingent valuation techniques are often constructed based on hypothetical market scenarios to reflect people's willingness to pay for environmental benefits or avoidance of cost. Also, contingent valuation enables estimation of the values placed on a particular environmental good or service by an individual, by creating a hypothetical market place; which enables the people to directly report their willingness to pay for such goods or services. The CV considers measuring the value of an environmental good or service holistically, by describing the resources to be valued and specifying what needs to change or protected (Garrod \& Willis, 2001), hence, nothing is revealed about the specific attributes of the resource. However, people's behaviour or their choice for change in a given environmental scenario, can be influenced by their difficulty to express their judgement or inability to understand how public policies actions are evaluated as captured by the questionnaire (Basili et al., 2006). Unlike the choice experiment (CE) method where an individual is given an array of options to choose, the $\mathrm{CV}$ method considers the dichotomous choice questions where people are asked to choose or make their choice based on two already specified options.

In this study, as specified in the choice experiment, the status quo is characterized by bad scenarios including high unemployment rate, pollution from oil spills, pipeline explosions, food safety risks and poverty, but without any payment cost (tax) on the people. By this experiment, people have the discretion to choose suitable trade-offs that would be better than the status quo, with improvements in the environment and their livelihood. In view of this background, this study aimed to draw econometric inferences from the willingness to pay (WTP) approach of environmental valuation. The study applied the Bayesian approach to estimate people's willingness to pay (WTP) for mitigation of environmental hazards in oil producing areas in Nigeria. The specific objectives of the study include the following to:

design a choice experiment to enable resource valuation using selected environmental and welfare attributes.

design a choice experiment to enable determination of WTP method of resource valuation for mitigation of undesirable impacts of resource exploitation as a result of crude oil extraction.

determine WTP estimates using the Bayesian approach.

make suggestions towards enhancing policy formulations and strategies to promote mitigation of environmental and livelihood impacts of resource exploitation in Nigeria.

\section{DATA AND METHODS}

The study was carried out in Southern Nigeria, involving 446 respondents selected from fifteen communities in the oil producing areas of the Niger Delta region of Nigeria. Five communities were selected in each of the states. An appropriate sampling frame was difficult to decide for this study because of lack of adequate data on local population of the study areas within the period of the research, thus, sampling was fairly pragmatic to enable getting a good sample size for the study. Selection of communities for the study was not entirely random. The three states were selected because of the presence of major oil and gas companies and history of negative impacts of the oil industry especially pollution. In other words, selection of the communities was guided by this information and was based on prejudice as communities selected for the study were mainly oil producing communities, communities with oil and gas facilities such as oil wells, oil and gas pipelines, and communities with reported environmental and livelihood impacts of oil and gas extraction. Also, logistical convenience was considered as the three states are close to each other and share adjoining boundaries. These communities were selected from three out of the nine oil producing states of the Niger Delta region in Southern Nigeria. These include: Akwa Ibom State: Edo, Iko, Mkpanak, Unyenge, and Ukpenekang. Bayelsa State: Odi, Imiringi, Etiama, Okotiama-Gbarain, and Ogboibiri. Rivers State: Chokota community, Igbo-Etche, AlesaEleme, Obigbo, and Biara.

At most thirty (30) people were interviewed in each of the communities using the Choice Experiment (CE) methodology involving choice sets. Data were collected through semi-structured survey questionnaires consisting the choice experiments; the choice cards. The choice cards were incorporated in a survey questionnaire such that each respondent responded to eight (8) choice cards. Choice sets (choice cards) were designed to include nice (9) attributes (eight including environmental and welfare attributes) and the status quo (representing current environmental and welfare situation in the study area). The choice sets consist attributes, varying levels of the 
attributes, and different payment options from which respondents chose based on their preferences. The Bayesian approach was used to estimate the willingness to pay values using the Mixed Logit model, as briefly described in the subsequent section. The study relied on inferences from the results of the WTP estimates in proffering suggestions toward mitigating environmental and welfare problems caused by the oil and gas industry.

\section{The Model Specification}

The model specification was guided by the assumption that majority of the people in the study area do not like the prevailing environmental and livelihood conditions. As would further be explained, the status quo was assumed to be characterised by negative impacts of the oil and gas industry with consequent environmental and livelihood problems in the study area. Hence, it was assumed that an individual would not like to pay for the status quo, rather would support a change in policies or pay for a change that would enhance mitigation of these impacts or an improvement to the status quo. Environmental problems identified in this study against which the WTP study was proposed include land-take by oil firms and occupied by various oil and gas facilities such as pipelines, which reduces the size and proportion of land available for agriculture, oil spill which causes land and water pollution, gas flaring with its accompanying health effects, as well as pipeline explosion. The welfare and livelihood issues include unemployment, poverty and food safety issues. With reference to the choice experiment designed for this study, the model was specified with the assumption that individuals would make a choice from which they would receive Utility (Eq. 1).
$U_{j, s, n}=X_{j, s, n} g\left(\beta_{j}\right)+\varepsilon_{j, s, n}$

Where,

$U_{j, s, n}$ denotes the Utility received by an individual, $\mathrm{j}$ ( $j t h$ individual), from the $s t h$ choice in the $n t h$ choice set. $X_{j, s, n}$ indicates the $(\mathrm{K} \times 1)$ vector of attributes presented to the $j$ th individual (where, $\mathrm{j}=1, \ldots, \mathrm{J}$ ) in the $s t h$ option (where, $\mathrm{s}=1, \ldots, \mathrm{S}$ ) of the nth choice set (where, $\mathrm{n}=1, \ldots, \mathrm{N}$ ). Otherwise, $y_{j, s, n}$ denotes an indicator variable that equals 1 if the $j t h$ individual indicates that they would choose the sth option within the $n t h$ choice set, and 0 if they would not. $\beta_{j}$ is a $(\mathrm{Kx} 1)$ vector indicating the preferences of the $j$ th individual and $g($.$) is a transformation of the$ parameters from and to the space of $\mathrm{k}$ vectors. $\varepsilon_{j, s, n}$ denotes the error which is uncorrelated across individuals and choices, and independent of $X_{j, s, n}$. For simplicity of this piece, specification of priors and misreporting are not reported, nevertheless, for reference purposes, an in-depth description of the Utility model, with specifications of priors and misreporting under the mixed logit model with Bayesian estimation are presented by Balcombe $\boldsymbol{e t} \boldsymbol{a l}$. (2009).

\section{RESULTS AND DISCUSSION}

\section{Description of Attributes}

Eight attributes were used in the choice experiment (CE), these include; tax, land, unemployment, land and water pollution by oil spill, gas flaring, poverty, food safety and pipeline explosion. The status quo was introduced as the ninth attributes as a control variable in the model. A summary description of the attributes is presented in Table 1 .

Table 1 Description of attributes used in the Choice Experiment

\begin{tabular}{|c|c|c|c|}
\hline Attributes & Labels & Description & Levels \\
\hline TAX & Tax & $\begin{array}{l}\text { A payment plan proposed in the form of tax or a } \\
\text { compulsory levy to enhance government policies } \\
\text { proposed to regulate the operations of the O\&G } \\
\text { industry, toward achieving a change to mitigate } \\
\text { the impacts of the industry. }\end{array}$ & $\begin{array}{l}0,100,200,300,400,500 \\
(0)^{*}\end{array}$ \\
\hline LANDOCC & $\begin{array}{l}\text { Land occupied by } \\
\text { O\&G pipelines }\end{array}$ & $\begin{array}{l}\text { Proposed reduction in the area of land occupied by } \\
\text { O\&G pipeline. }\end{array}$ & $\begin{array}{l}0,10,20,30,40,50 \\
(4500 \mathrm{~km}) *\end{array}$ \\
\hline UNEMP & Unemployment & Proposed reduction in unemployment rate. & $20,25,30,35(20 \%)^{*}$ \\
\hline SPILL & $\begin{array}{l}\text { Land and water } \\
\text { pollution by oil } \\
\text { spill }\end{array}$ & Proposed reduction in oil spills cases. & $\begin{array}{l}0,10,20,30,40,50,60 \\
(320)^{*}\end{array}$ \\
\hline GFLARE & $\begin{array}{l}\text { Amount of gas } \\
\text { flared per year }\end{array}$ & Proposed reduction in gas flaring. & $\begin{array}{l}0,5,10,15,20,25 \\
(2.5)^{*}\end{array}$ \\
\hline POVERTY & Poverty & Proposed reduction in poverty rate. & $\begin{array}{l}63,65,68,70,75 \\
(63 \%)^{*}\end{array}$ \\
\hline FOODSAF & Food Safety & $\begin{array}{l}\text { Proposed reduction in the percentage of } \\
\text { contaminated (unsafe) food in the market. }\end{array}$ & $1,2,3,5,7,10(10 \%)^{*}$ \\
\hline PEXPLO & $\begin{array}{l}\text { Number of Pipeline } \\
\text { explosions per year }\end{array}$ & $\begin{array}{l}\text { Proposed reduction in the number of pipeline } \\
\text { explosions. }\end{array}$ & $2,5,7,9,11,15(15)^{*}$ \\
\hline Status Quo & STATQUO & $\begin{array}{l}\text { A hypothetical base level or current scenario from } \\
\text { which the changes are prescribed. The levels of } \\
\text { the status quo remain the same in all the choice } \\
\text { sets. }\end{array}$ & \\
\hline
\end{tabular}

NB: All attributes were assigned levels and payment options from which mitigation was proposed. *Figures in parentheses are base levels for the respective attributes. 
In this study, the status quo represents a hypothetical base level or prevailing scenario from which the changes or deviations in other attributes were proposed. The levels of the status quo remained the same in all the choice sets. It was assumed that people do not like the prevailing situations (the status quo), hence would prefer a change that would bring about mitigation of the ne gative impacts of resource exploitation with regards to the environment and people's livelihood.

\section{Willingness to pay estimations}

The Bayesian approach was used to estimate the mixed logit model employing the normal and log-normal distributions of the parameters. The normal distribution allows the assumption that the distribution though not known, but assumed to be normally distributed, and the variables are within any two real number limits. Under the lognormal distribution, the parameters were modelled and restricted to assume positive real values with the assumption that the mean and variance are fixed. The results were generated after 10,000 iterations (simulations), to ensure reduction in error variance. The WTP estimates based on the Bayesian approach are presented in Table 2.

Table 2 presents the WTP estimates based on the distributions of the parameters under normal and lognormal distributions. The results presented are the median WTPs unlike the classical approach where the mean WTPs were presented (Table 3). It was observed that the median WTPs under the Bayesian approach are more stable than the mean WTPs over various stimulations. Comparatively, the WTP estimates under the Log-normal distribution appear higher than that of the normal distribution and the classical approach. The result also shows people's willingness to pay a high amount of tax for a reduction in the percentage of unsafe food in the markets (FOODSAF), reduction in poverty rate (POVERTY) and unemployment rate (UNEMP). With a negative WTP estimate for the status quo (-6.07 under the normal distribution and -9.95 under the log-normal distribution), the results indicate people's willingness to pay for an improvement in the status quo, which indicates an indication of people's willingness to avert environmental problems and poor welfare conditions. On the other hand, the result also indicates positive WTP coefficients for reduction in pipeline explosion (PEXPLO), reduction in land and water pollution from oil spills (SPILL), reduction in displacement of land by oil and gas pipelines (LOCC), and reduction in gas flaring (GFLARE), suggesting that majority of the people are willing to pay to ensure reduction in pollution, gas flaring and land take by oil and gas companies. Most of the rural oil producing communities depend largely on land for farming, and water resources for fishing, thus, farming and fishing households face avoidable risks of poor income, food insecurity and poverty, in the event of an oil spill. Pipeline explosion has been the cause of most oil spills and fire outbreaks, especially in the event of sabotage, and it is known to have resulted in massive destruction of farms, forest and human settlements, coupled with severe environmental pollution affecting air, land and water. Anifowose (2014) also shares the views that oil pipeline constructed across Nigeria most of which are within the Niger delta region, has made the region vulnerable to explosions and oil spills as a result of deliberate damaging of the pipelines in the acts of vandalism and sabotage or due to faulty obsolete pipes. Pipeline explosion is a severe hazard of the oil and gas industry, which in most cases, causes death and injury to both animals and human beings, and a wide range of damage to the environment and people's sources of livelihood (Han \& Weng, 2010). These environmental impacts pose serious setback on agricultural production and food security among rural households in the oil producing areas in Nigeria (Ukpong, \& Obok, 2018). In fact, majority of the rural households in Nigeria depend largely on subsistent agriculture, fishing and forestry activities (Ekpebu \& Ukpong, 2013).

On the whole, the results suggest that if the O\&G companies provide livelihood improvements (such as employment, poverty reduction, and reduction in food safety risks), the people might be willing to bear some of the negative impacts of the industry. In particular, WTP coefficients for these attributes were comparatively higher compared to WTP for reduction in gas flaring. Beside the implications of the negative impacts of the $\mathrm{O} \& \mathrm{G}$ industry whereby people are willing to pay to promote mitigation measures, the comparatively low WTP coefficients for gas flaring might suggests poor awareness of the negative effects of flaring (particularly, long-term impacts including health problems), despite being one of the major environmental problems of global concerns.

For the purpose of comparison, the mean WTPs are presented in Table 3.

Recall that median WTPs were reported in Table 2, which show a slide variance from the mean WTPs presented in Table 3. Despite the slide difference in the means and medians WTPs, the results seem to corroborate with WTP results reported by Balcombe et al. 2009, where the means and medians WTPs are almost identical. The close similarity in the mean and median values for WTPs suggests the normality of the WTP distributions, nevertheless, the difference between the mean WTPs and median WTPs may be attributed to simulation error, also the influence of outliers and misreporting cannot be underestimated.

Like the result of the WTP estimates presented in Table 2, the results in Table 3, above shows the mean WTP in Nigerian currency, Naira $(\mathrm{N})$, for each of the attributes specified in the choice experiment. The result shows a negative but a high mean WTP for the status quo, suggesting people's willingness to pay less to maintain the status quo, but a higher premium (N7.91) either to avoid the status quo or achieve an improved scenario. The mean WTP for FOODSAF is comparatively the highest, indicating that on the average, people are willing to pay as much as $\mathrm{N} 23.12$ for a reduction in the number of unsafe food (or contaminated food) in the market. Poverty rate and unemployment rate also have high WTPs, indicating that on the average, the people are willing to pay as much as N12.88 and N11.78 respectively to promote at least a $1 \%$ reduction in poverty rate and unemployment rate in the study area. 
Table 2 WTP Estimates (Bayesian Approach)

\begin{tabular}{lllllll}
\hline Variable & \multicolumn{2}{l}{ Normal Distribution } & \multicolumn{4}{l}{ Log-Normal Distribution } \\
& Median & Lower Quartile & Upper Quartile & Median & Lower Quartile & Upper Quartile \\
\hline TAX (Price) & 1.00000 & 1.00000 & 1.00000 & 1.00000 & 1.00000 & 1.00000 \\
LOCC & 2.37980 & -0.00312 & 4.95505 & 2.63809 & 0.18793 & 5.36962 \\
PEXPLO & 5.90083 & 1.30506 & 13.72184 & 8.92944 & 2.34030 & 23.25713 \\
SPILL & 2.42151 & 0.85201 & 4.26765 & 2.64103 & 0.95431 & 4.62023 \\
GFLARE & 0.12732 & -0.86885 & 1.18112 & 0.23928 & -0.86846 & 1.57384 \\
UNEMP & 10.27993 & 4.75074 & 20.60551 & 14.96370 & 6.31858 & 32.71921 \\
POVERTY & 10.44142 & 6.35686 & 18.33676 & 14.69053 & 7.11321 & 29.82153 \\
FOODSAF & 19.82191 & 8.98767 & 34.67057 & 25.55135 & 14.15675 & 43.39659 \\
STATQUO & -6.07222 & -11.0203 & -3.67492 & -9.94515 & -18.5842 & -5.32510 \\
\hline
\end{tabular}

Table 3. Means, Standard Deviations and Standard Errors for Marginal Utilities

\begin{tabular}{lcccc}
\hline Attribute & Mean WTP & Coefficient $(\beta)$ & $\begin{array}{c}\text { Standard } \\
\text { Deviation }\end{array}$ & Standard Error \\
\hline TAX (Price) & 1.0000 & 0.0511 & 0.0360 & 0.0033 \\
LOCC & 2.1460 & 0.1100 & -0.0179 & 0.0029 \\
PEXPLO & 9.4530 & 0.4830 & -0.0449 & 0.0076 \\
SPILL & 2.5510 & 0.1300 & -0.0182 & 0.0027 \\
GFLARE & 0.2960 & 0.0150 & 0.0003 & 0.0037 \\
POVERTY & 12.8811 & 0.6580 & -0.0925 & 0.0099 \\
UNEMP & 11.7754 & 0.6010 & 0.0002 & 0.0167 \\
FOODSAF & 23.1231 & 1.1800 & -0.1109 & 0.0117 \\
STATQUO & -7.9077 & -0.4369 & 0.5652 & 0.3051 \\
\hline
\end{tabular}

The result also suggests that people are also willing to pay as much as $\mathrm{N} 2.15$, to ensure at least a $1 \%$ reduction in the size of land occupied by oil and gas pipeline, while the mean WTP for SPILL was estimated at N2.55, suggesting people's willingness to pay to secure at least a $1 \%$ reduction in oil spill resulting in land and water pollution. In summary, the government and oil industry are encouraged to come up with technology, or a mitigation plan or policy that would promote the use of less area of land for construction of oil and gas pipelines and other facilities. Also, the result further indicates that the least attribute the people would be willing to pay for is gas flaring, with the estimated mean WTP of N0.30, indicating a comparatively low payment for gas flaring which may be due to poor awareness of the dangers of gas flaring among majority of the people.

\section{CONCLUSIONS}

Most rural population in Southern Nigeria depend largely on the natural environment for their livelihood, engaging in agriculture, fishing and forestry activities. In particular, apart from those in the coastal and forested areas, majority of the households are largely engaged in crop farming and small-scale animal production. Located in oil and gas producing areas, the environment and indeed people's sources of livelihood face persistent limitations posed by impacts of crude oil extraction and transportation. The study aimed to draw econometric inferences from the willingness to pay (WTP) approach to environmental valuation and applied the Bayesian approach to estimate people's willingness to pay (WTP) for mitigation of environmental hazards in oil producing areas in Southern
Nigeria. The model estimates indicating a negative WTP for the STAQUO indicates that people do not like the prevailing environmental problems and poor welfare situation in the area which is as a result of oil and gas extraction. The results also show a comparatively higher willingness-to-pay to achieve food safety, poverty reduction and reduction in unemployment rate respectively, suggesting people's desire for mitigation of undesirable livelihood and welfare impacts of resource exploitation. The results also indicate high WTP values for reduction in pipeline explosion, oil spill, land occupied by $\mathrm{O} \& \mathrm{G}$ pipelines and gas flaring, suggesting that majority of the people are willing to support mitigation measures and policies that would ensure such reductions. By inference, the literary significance of 'pay' depicts the readiness to be involved in the process that will bring about a change in the current undesirable condition (the status quo) caused by resource exploitation. This does not only suggest a non-tax protest scenario, but also a rejection of the negative effects associated with $O \& G$ extraction, and the extent to which the people place value for improvements in the environment and their livelihood. In other words, it suggests the need for a change from the status quo (characterized by pollution and negative livelihood impacts), and the high values attached by individuals to promote mitigation measures that would enhance reduction in pollution, poverty and unemployment, as well as, improvement in food safety in the oil producing areas. Beyond the issue of impact mitigation in the context of this study, findings on people's WTP may also be useful to the government and policy makers in the bid to achieve a viable and feasible construct for Nigeria's tax system. 
With regards to the comparatively low WTP coefficients reported for gas flaring, there is a need for public awareness on the impacts of gas flaring to help the people protect themselves from avoidable exposures. Oil and gas $(\mathrm{O} \& \mathrm{G})$ companies are encouraged to ensure mitigation of environmental and livelihood impacts of crude oil and gas extraction with reference to environmental laws and global best drilling practices. These should include reduction in gas flaring as Nigeria seems to flare more gas than other oil producing nations. The study also recommends increased investment in research and technology to promote efficient use of supposed flared gas by the O\&G industry. On the other hand, with regards to the environment and human livelihood, agriculture remains a vital economic leverage for the people, thus effective mitigation measures would promote environmental productivity and sustainably improve human livelihoods. The study further recommends application of the willingness to pay approach as an important strategy for assessing the values of public resources. In addition, this study also recommends application of other model forms such as the Bayesian Infinite Mixture Logit (BIML), Fixed Parameter Logit model (FPL) and Hierarchical Bayes Logit Model (HBL) to enable comparisons with the Mixed Logit model applied in this study.

\section{Acknowledgement}

Author acknowledges the supervisory assistance from Professor Kelvin Balcombe and Dr. Francisco Areal of the University of Reading, United Kingdom, for the research from which this paper is extracted.

\section{REFERENCES}

ACOSTA, L. A., EUGENIO, E. A., ENANO, N. H., MAGCALE-MACANDOG, D. B., VEGA, B. A., MACANDOG, P. B. M. and LUCHT, W. (2014). Sustainability trade-offs in bioenergy development in the Philippines: An application of conjoint analysis. Biomass and Bioenergy, 64, 20-41. DOI: $\underline{\text { 10.1016/j.biombioe.2014.03.015. }}$.

AMIGUES, J. P., BOULATOFF, C., DESAIGUES, B., GAUTHIER, C. and KEITH, J. E. (2002). The benefits and costs of riparian analysis habitat preservation: a willingness to accept/willingness to pay contingent valuation approach. Ecological Economics, 43(1), 17-31. DOI: 10.1016/s0921-8009(02)00172-6.

AKUJURU, V. A. and RUDDOCK, L. (2014). Incorporation of Socio-Cultural Values in Damage Assessment Valuations of Contaminated Lands in the Niger Delta. Land,3(3), 675-692. DOI: 10.3390/land3030675.

ANIFOWOSE, B., LAWLER, D., HORST, D. and CHAPMAN, L. (2014). Evaluating interdiction of oil pipelines at river crossings using Environmental Impact Assessments. Area, 46(1), 4-17. DOI: 10.1111/area.12065/full.

BACHMANN, T. M. and VAN DER KAMP, J. (2014). Environmental cost-benefit analysis and the EU (European Union) Industrial Emissions Directive: Exploring the societal efficiency of a DeNOx retrofit at a coal-fired power plant. Energy, 68, 125-139. DOI: 10.1016/j.energy.2014.02.051.

BALCOMBE, K., CHALAK, A. and FRASER, I. (2009). Model selection for the mixed logit with Bayesian estimation. Journal of Environmental Economics and Management, 57, 226-237. DOI: 10.1016/j.jeem.2008.06.001.

BASILI, M., DI MATTEO, M. and FERRINI, S. (2006). Analysing demand for environmental quality: A willingness to pay/accept study in the province of Siena (Italy). Waste Management, 26(3), 209-219. DOI: 10.1016/j.wasman.2004.12.027.

EKPEBU, I. D. and UKPONG, I. G. (2013). Rethinking Agricultural Development in Nigeria: Paradox of Oil Wealth. Authorhouse Publishing: Bloomington, USA.

FULEKY, P., ZHAO, Q. and BONHAM, C. S. (2014). Estimating demand elasticities in non-stationary panels: The case of Hawaii tourism. Annals of Tourism Research, 44, 131-142. DOI: 10.1016/j.annals.2013.09.006.

GARROD, G. AND WILLIS, K. G. (1999). Economic Valuation of the Environment: Methods and Case Studies (p. 384). Cheltenham: Edward Elgar.

HAN, Z. and WENG, W. (2010). An integrated quantitative risk analysis method for natural gas pipeline network. Journal of Loss Prevention in the Process Industries, 23(3), 428-436. DOI: 10.1016/j.jlp.2010.02.003.

HAINMUELLER, J., HOPKINS, D. J. and YAMAMOTO, T. (2014). Causal inference in conjoint analysis: Understanding multidimensional choices via stated preference experiments. Political Analysis, 22(1), 1-30. DOI: $10.1093 / \mathrm{pan} / \mathrm{mpt024}$.

JANG, J., LEE, J. and YOO, S. H. (2014). The public' s willingness to pay for securing a reliable natural gas supply in Korea. Energy Policy, 69, 3-13. DOI: 10.1016/j.enpol.2014.02.035.

LIENHOOP, N. and MACMILLAN, D. (2007). Valuing wilderness in Iceland: estimation of WTA and WTP using the market stall approach to contingent valuation. Land Use Policy, 24(1), 289-295. DOI: 10.1016/j.landusepol.2005.07.001.

LOOMIS, J. and MCTERNAN, J. (2014). Economic value of instream flow for non-commercial whitewater boating using recreation demand and contingent valuation methods. Environmental management, 53(3), 510-519. DOI: $10.1007 / \mathrm{s} 00267-014-0232-\mathrm{z}$.

NIJKAMP, P., VINDIGNI, G. and NUNES, P. A. (2008). Economic valuation of biodiversity: A comparative study. Ecological economics,67(2), 217-231. DOI: 10.1016/j.ecolecon.2008.03.003.

PIRIYAPADA, S. and WANG, E. (2014). Quantifying the Costs and Benefits of Coastal Water Quality Improvements in the Ko Chang Marine National Park, Thailand. Environmental Processes, 1(2), 149-169. DOI: 10.1007/s40710-014-0013-y.

RAO, V. R. (2014). In: RAO, V. R. (2014). Applications for Pricing Decisions. In Applied Conjoint Analysis (pp. 291-316). Springer: Berlin Heidelberg.

UKPONG, I. G. and OBOK, E. (2018). Implications of Crude Oil Extraction on Agriculture and Livelihood in Oil Producing Rural Communities in Nigeria. Review of 
Agricultural and Applied Economics 21 (2) 71-77. DOI: 10.15414/raae/2018.21.02.71-77.

VAN BERKEL, D. B. and VERBURG, P. H. (2014). Spatial quantification and valuation of cultural ecosystem services in an agricultural landscape. Ecological Indicators, 37 , 163-174.

DOI: 10.1016/j.ecolind.2012.06.025.

ZENELI, M. (2014). Method for Economic Assessment of Regulatory Impact (Ria) in Albania. Advantages and Disadvantages of Economic and Inference Methods. Journal of Educational and Social Research, 4(2), 348. DOI: 10.5901/jesr.2014.v4n2p348.
ZHENG, S., CAO, J., KAHN, M. E. and SUN, C. (2014). Real estate valuation and cross-boundary air pollution externalities: evidence from Chinese cities. The Journal of Real Estate Finance and Economics, 48(3), 398-414. DOI: $10.1007 / \mathrm{s} 11146-013-9405-4$. 